\title{
Correlation of osteoarthritis or rheumatoid arthritis with bone mineral density in adults aged $20-59$ years
}

\author{
Zhongxin Zhu ${ }^{1,2}$, Gangfeng $\mathrm{Hu}^{1}$, Fang $\mathrm{Jin}^{1}$ and Xiaocong Yao ${ }^{1 *}$ (D)
}

\begin{abstract}
Background: It is reported that osteoporosis commonly occurs among patients with rheumatoid arthritis (RA), whereas the association between osteoporosis and osteoarthritis (OA) remains controversial. Our aim in this study was to investigate the association between BMD, as a marker of osteoporosis, and OA and RA among adults 20-59 years of age, using a population-based sample from the National Health and Nutrition Examination Survey (NHAN ES).

Methods: Our analysis was based on the NHANES data collected between 2011 and 2018. Data regarding arthritis status and the type of arthritis (OA or RA) were obtained from questionnaires. Lumbar BMD was measured by dualenergy $\mathrm{X}$-ray absorptiometry. The association between OA, RA, and lumbar BMD was evaluated using logistic regression models. Subgroup analyses, stratified by gender and race, were performed. The association between duration of arthritis and lumbar BMD was also investigated.
\end{abstract}

Results: A total of 11,094 adults were included in our study. Compared to the non-arthritis group, participants with OA had a higher lumbar BMD ( $\beta=0.023,95 \% \mathrm{Cl} 0.011-0.035)$, with no significant association between lumbar BMD and RA ( $\beta=0.014,95 \% \mathrm{Cl}-0.003$ to 0.031 ). On subgroup analyses stratified by gender, males with OA had a higher lumbar BMD compared to those without OA ( $\beta=0.047$, 95\% Cl 0.028-0.066). In females, OA was not associated with lumbar $\mathrm{BMD}(\beta=0.007,95 \% \mathrm{Cl}-0.008$ to 0.021$)$. There was no association between lumbar BMD and RA in both males $(\beta=0.023,95 \% \mathrm{Cl}-0.003$ to 0.048$)$ and females $(\beta=0.008,95 \% \mathrm{Cl}-0.015$ to 0.031$)$. Duration of arthritis was not associated with lumbar BMD for both $\mathrm{OA}(\beta=-0.0001,95 \% \mathrm{Cl}-0.0017$ to 0.0015$)$ and RA ( $\beta=0.0006,95 \% \mathrm{Cl}-0.0012$ to 0.0025$)$.

Conclusions: Lumbar BMD was associated with OA but not with RA. While a higher lumbar BMD was associated with $\mathrm{OA}$ in males, but not in females. Our findings may improve our understanding between OA, RA, and bone health.

Keywords: Osteoarthritis, Degenerative arthritis, Rheumatoid arthritis, Bone health, NHANES

\footnotetext{
* Correspondence: hzyaoxiaocong@163.com

${ }^{1}$ Department of Osteoporosis Care and Control, Xiaoshan Affiliated Hospital of Wenzhou Medical University, Hangzhou 311200, Zhejiang, China

Full list of author information is available at the end of the article
}

C C The Author(s). 2021 Open Access This article is licensed under a Creative Commons Attribution 4.0 International License, which permits use, sharing, adaptation, distribution and reproduction in any medium or format, as long as you give appropriate credit to the original author(s) and the source, provide a link to the Creative Commons licence, and indicate if changes were made. The images or other third party material in this article are included in the article's Creative Commons licence, unless indicated otherwise in a credit line to the material. If material is not included in the article's Creative Commons licence and your intended use is not permitted by statutory regulation or exceeds the permitted use, you will need to obtain permission directly from the copyright holder. To view a copy of this licence, visit http://creativecommons.org/licenses/by/4.0/ The Creative Commons Public Domain Dedication waiver (http://creativecommons.org/publicdomain/zero/1.0/) applies to the data made available in this article, unless otherwise stated in a credit line to the data. 


\section{Introduction}

Osteoporosis (OP), osteoarthritis (OA), and rheumatoid arthritis (RA) are pathologies of the musculoskeletal system that cause pain, movement impairments, and possibly permanent disability [1]. With aging of the general population, it is estimated that 1 in 4 adults in developed countries are affected by OP, OA, and/or RA $[2,3]$. The pathophysiology of these three conditions is different; however, RA is an autoimmune disease of unknown etiology, associated with a homeostatic imbalance [4]. By contrast, OA is largely considered a biomechanical disorder of articular joints, with its onset and development being closely related to changes in inflammatory and catabolic functions of the body [5]. OP is a systemic disease associated with a marked loss of bone mineral density (BMD). As two notable silent rheumatic diseases, OA and OP have been included on the World Health Organization's list of disabling disease $[1,6]$.

However, a clear association between OP and OA has not been clearly defined and remains an issue of controversy, while OP is commonly associated with RA [7-10]. Our aim in this study was to investigate the association between BMD, as a marker of OP, and OA and RA among adults $20-59$ years of age, using a populationbased sample from the National Health and Nutrition Examination Survey (NHANES).

\section{Methods}

\section{Study population}

The NHANES program is a series of surveys focusing on the health topics of the general population, of all ages, in the United States (US). A multistage, complex clustered, probability design is used for data collection and analysis, rather than being based on a simple random sample of the US population [11].

For our study, we used NHANES data collected between 2011 and 2018. The study population was restricted to adults $20-59$ years of age $(n=14,934)$. From this eligible group, 3840 individuals were excluded for the following reasons: absence of an arthritis diagnosis $(n=23)$ or lumbar BMD measure $(n=3398)$, or a cancer diagnosis $(n=419)$ were excluded. A total of 11,094 individuals were included in our analysis.

Our study protocol was approved by the ethics review board of the National Center for Health Statistics (NCHS). Within the NHANES program, all participants have provided consent for the use of their anonymized information for research purposes [12].

\section{Arthritis}

A diagnosis of arthritis was based on the medical conditions questionnaires collected by interview as part of the NHANES program. Participants were asked if they had ever been told by their doctor or other health professional that they had arthritis. If "yes", they were asked to classify their arthritis diagnosis as OA, RA, psoriatic arthritis, other, or do not know/refuse to answer. The duration of arthritis was determined in years as the "age at screening" minus the "age at the time of diagnosis."

\section{Lumbar BMD}

The lumbar spine is one site that is typically evaluated for the assessment and treatment of OP, with BMD measurement at this site having been used as a marker of OP in clinical trials for over three decades [13]. BMD measures within the NHANES were obtained using dual-energy X-ray absorptiometry (DXA) scans, which is the most widely accepted method. Within the NHANES program, DXA scans were performed using a Hologic Discovery model A densitometers (Hologic, Inc., Bedford, Massachusetts), with data analyzed using Hologic APEX (version 4.0) software. Further details of the DXA examination protocol are available on the NHANES website.

\section{Collected data}

The following demographic data were collected by interview questionnaires: age, gender, race, educational level, ratio of family income to poverty, vigorous recreational activities, and smoked history. Race was quantified as follows: non-Hispanic White, non-Hispanic Black, Mexican American, other Hispanic, and other race, including being multi-racial. Vigorous recreational activities was based on an individual's self-reported answer to the following question: "Do you do any vigorous-intensity sports, fitness, or recreational activities that cause large increases in breathing or heart rate like running or basketball for at least 10 minutes continuously?." A positive smoking history was defined as $\geq 100$ cigarettes smoked in one's life.

\section{Laboratory data}

Biospecimens were collected for laboratory analysis to provide detailed information on each individual's nutritional status and general health. Biospecimens were collected, processed, and stored in the mobile examination center until shipping to a laboratory for analysis. The following biomarkers were collected: blood urea nitrogen, total protein, total cholesterol, alkaline phosphatase, serum potassium, serum sodium, serum phosphorus, serum uric acid, and serum calcium.

\section{Statistical analysis}

To assure national representation, we used weighted analyses as recommended by the analytical guidelines of the NCHS. The $P$ value of the difference between individuals with and without arthritis was calculated using a 
weighted chi-squared test for categorical variables and a weighted linear regression model for continuous variables.

The association between arthritis (OA and $\mathrm{RA}$ ) and lumbar BMD was examined using a multivariable logistic regression. Three models were constructed, as follows: model 1, no adjustment for covariates; model 2, adjusted for age, gender, and race; model 3, adjusted for age, gender, race, educational level, body mass index (BMI), ratio of family income to poverty, vigorous recreational activities, smoked history, blood urea nitrogen, total protein, total cholesterol, alkaline phosphatase, serum potassium, serum sodium, serum phosphorus, serum uric acid, and serum calcium were adjusted. In addition, in alignment with The Strengthening the Reporting of Observational Studies in Epidemiology (STROBE) guideline [14], we performed subgroup analyses, stratified by age and gender, to make better use of the data. We also performed multivariable logistic regression to explore the association between duration of $\mathrm{OA}$ and RA and lumbar BMD. All analyses were performed using package $\mathrm{R}$ (version 3.4.3, http://www.Rproject.org) and EmpowerStats software (http://www. empowerstats.com). The significance level was set at 0.05 for all analyses.

\section{Results}

\section{Study sample}

The characteristics of the samples are presented in Table 1 , with relevant features between the non-arthritis and arthritis group summarized, as follows. Compared to the non-arthritis group, the arthritis group was older (mean age $37.59 \pm 11.34$ years versus $47.99 \pm 9.36$ years), and had a higher proportion of women than men $(46.17 \%$ versus 56.08\%). Race, educational level, BMI, vigorous recreational activities, smoked history, blood urea nitrogen, total protein, total cholesterol, alkaline phosphatase, serum uric acid, serum sodium, and serum calcium were also significantly different between the two groups $(P<$ 0.05).

\section{Multiple regression model}

As shown in Table 2, the association between arthritis and lumbar BMD was not significant in the unadjusted model $(\beta=0.007,95 \%$ CI -0.001 to 0.015$)$. However, a significant association between arthritis and lumbar BMD was identified after adjusting for age, gender, and race (model 2: $\beta=0.017$, 95\% CI $0.008-0.025$; model 3: $\beta=0.018,95 \%$ CI $0.010-0.027)$. Compared to the nonarthritis group, individuals with $\mathrm{OA}$ or degenerative arthritis had a higher lumbar BMD $(\beta=0.023,95 \%$ CI 0.011-0.035), with no significant association between the lumbar BMD and RA $(\beta=0.014,95 \% \mathrm{CI}-0.003$ to $0.031)$.

\section{Subgroup analyses}

In the subgroup analyses stratified by gender (Table 3 ), the lumbar BMD was higher among males with OA or degenerative arthritis than those without $(\beta=0.047,95 \%$ CI 0.028-0.066). However, among females, lumbar BMD was not related to $\mathrm{OA}$ or degenerative arthritis $(\beta=$ $0.007,95 \% \mathrm{CI}-0.008$ to 0.021$)$. There was no association between lumbar BMD and RA in either males $(\beta=$ $0.023,95 \% \mathrm{CI}-0.003$ to 0.048$)$ or females $(\beta=0.008$, $95 \%$ CI -0.015 to 0.031 ).

In the subgroup analyses stratified by race (Table 4), non-Hispanic White adults with $\mathrm{OA}$ or degenerative arthritis had a higher lumbar BMD compared to those without ( $\beta=0.014,95 \% \mathrm{CI}-0.003$ to 0.031 ).

\section{Associations between disease duration and lumbar BMD}

As shown in Table 5, there was no association between the lumbar BMD and either OA or degenerative arthritis $(\beta=-0.0001,95 \% \mathrm{CI}-0.0017$ to 0.0015$)$ or RA $(\beta=$ $0.0006,95 \% \mathrm{CI}-0.0012$ to 0.0025$)$.

\section{Discussion}

The main findings of our study were as follows: First is the positive association between a higher lumbar BMD and OA among males, but not among females. Second, there was no association between the lumbar BMD and RA, in both females and males.

The association between OP and OA has been an issue of controversy for a number of years. Both diseases depend on bone metabolism and are positively correlated with aging. In a study of 359 postmenopausal women 50-89 years of age, Povoroznyuk et al. [15] identified that women with symptomatic OA had a significantly higher lumbar BMD compared to controls. By contrast, a cross-sectional analysis of a Korean national survey reported a negative association between lumbar BMD and knee OA [16]. A recent prospective study provided strong evidence that high femoral neck BMD is a prognostic risk factor for the development of knee and hip radiographic OA [17]. In addition, higher BMD has been shown to reduce the risk of fractures among both men and women $[18,19]$. The concomitant presence of OP and $\mathrm{OA}$ in patients with hip or spine OA has also been reported [20, 21]. In a study of 80 post-menopausal women with hand OA, including Heberden's nodes which is a characteristic feature of primary generalized $\mathrm{OA}$, and 80 age-matched women without OA, the authors found that primary generalized OA is not protective against osteoporosis [22]. The results of a crosssectional study of 2855 individuals $\geq 40$ years of age identified a significant association between elevated phalangeal $\mathrm{BMD}$ and radiographic knee OA among women but not men [23]. 
Table 1 Characteristic of study sample with and without arthritis

\begin{tabular}{|c|c|c|c|}
\hline & Arthritis $(n=1510)$ & Non-arthritis $(n=9584)$ & $P$ value \\
\hline Age (years) & $47.99 \pm 9.36$ & $37.59 \pm 11.34$ & $<0.001$ \\
\hline \multicolumn{4}{|l|}{ Age groups } \\
\hline $20-29$ years & 5.97 & 30.31 & \multirow[t]{4}{*}{$<0.001$} \\
\hline $30-39$ years & 12.38 & 26.12 & \\
\hline $40-49$ years & 27.09 & 24.53 & \\
\hline $50-59$ years & 54.56 & 19.04 & \\
\hline \multicolumn{4}{|l|}{ Gender (\%) } \\
\hline Male & 43.92 & 53.83 & \multirow[t]{2}{*}{$<0.001$} \\
\hline Female & 56.08 & 46.17 & \\
\hline \multicolumn{4}{|l|}{ Race (\%) } \\
\hline Mexican American & 6.07 & 11.06 & \multirow[t]{5}{*}{$<0.001$} \\
\hline Other Hispanic & 5.07 & 7.71 & \\
\hline Non-Hispanic White & 68.41 & 58.80 & \\
\hline Non-Hispanic Black & 12.47 & 12.32 & \\
\hline Other race-including multi-racial & 7.97 & 10.11 & \\
\hline \multicolumn{4}{|l|}{ Educational level (\%) } \\
\hline Less than 9th grade & 3.94 & 3.96 & \multirow[t]{6}{*}{$<0.001$} \\
\hline 9th-11th grade & 11.83 & 9.02 & \\
\hline High school graduate/GED or equivalent & 22.99 & 21.67 & \\
\hline Some college or AA degree & 35.13 & 32.47 & \\
\hline College graduate or above & 26.11 & 32.87 & \\
\hline Not recorded & 0 & 0.01 & \\
\hline Body mass index (kg/m2) & $31.71 \pm 8.00$ & $28.56 \pm 6.56$ & $<0.001$ \\
\hline Ratio of family income to poverty & $2.95 \pm 1.72$ & $2.94 \pm 1.66$ & 0.821 \\
\hline \multicolumn{4}{|l|}{ Vigorous recreational activities (\%) } \\
\hline Yes & 19.99 & 36.63 & \multirow[t]{2}{*}{$<0.001$} \\
\hline No & 80.01 & 63.37 & \\
\hline \multicolumn{4}{|l|}{ Smoked at least 100 cigarettes in life (\%) } \\
\hline Yes & 51.38 & 38.63 & \multirow[t]{3}{*}{$<0.001$} \\
\hline No & 48.59 & 61.35 & \\
\hline Not recorded & 0.03 & 0.02 & \\
\hline Blood urea nitrogen (mmol/L) & $4.82 \pm 1.71$ & $4.54 \pm 1.49$ & $<0.001$ \\
\hline Total protein $(\mathrm{g} / \mathrm{L})$ & $70.60 \pm 4.45$ & $71.58 \pm 4.29$ & $<0.001$ \\
\hline Total cholesterol (mmol/L) & $5.11 \pm 1.04$ & $4.91 \pm 1.02$ & $<0.001$ \\
\hline Alkaline phosphatase (U/L) & $71.50 \pm 22.57$ & $66.32 \pm 22.73$ & $<0.001$ \\
\hline Serum uric $\operatorname{acid}(\mu \mathrm{mol} / \mathrm{L})$ & $323.79 \pm 84.78$ & $318.53 \pm 80.72$ & 0.019 \\
\hline Serum sodium (mmol/L) & $139.12 \pm 2.43$ & $139.25 \pm 2.21$ & 0.037 \\
\hline Serum potassium (mmol/L) & $3.95 \pm 0.33$ & $3.97 \pm 0.31$ & 0.122 \\
\hline Serum phosphorus (mmol/L) & $1.20 \pm 0.17$ & $1.20 \pm 0.18$ & 0.397 \\
\hline Serum calcium (mmol/L) & $2.34 \pm 0.09$ & $2.34 \pm 0.08$ & 0.013 \\
\hline Disease duration of arthritis (years) & $9.20 \pm 8.90$ & / & \\
\hline \multicolumn{4}{|l|}{ Which type of arthritis was it? (\%) } \\
\hline Osteoarthritis or degenerative arthritis & 41.61 & / & \multirow[t]{2}{*}{ / } \\
\hline Rheumatoid arthritis & 17.45 & / & \\
\hline
\end{tabular}


Table 1 Characteristic of study sample with and without arthritis (Continued)

\begin{tabular}{llll}
\hline & Arthritis $(\boldsymbol{n}=\mathbf{1 5 1 0})$ & Non-arthritis $(\boldsymbol{n}=\mathbf{9 5 8 4})$ & $\boldsymbol{P}$ value \\
\hline Psoriatic arthritis & 2.73 & $/$ \\
Other & 0.17 & $/$ \\
Do not know or refused & 24.20 & $1.04 \pm 0.15$ \\
Lumbar bone mineral density $\left(\mathrm{g} / \mathrm{cm}^{2}\right)$ & $1.05 \pm 0.16$ & 0.086 \\
\hline
\end{tabular}

Mean \pm SD for continuous variables: $P$ value was calculated by weighted linear regression model

Percent for categorical variables: $P$ value was calculated by weighted chi-square test

The biologic mechanism by which BMD influences OA has not been established. Previous statistically significant findings may result from uncontrolled and unmeasured confounding factors, such as skeletal growth factors [24], bone geometry [25, 26], bone morphology [27], and genetics [28]. A previous cohort analysis from the Framingham Study reported that a higher BMD decreased the risk of progression of radiographic knee OA, defined by the presence of osteophytes on radiographs [29]. The authors postulated that a higher BMD reduced the risk of joint space loss; however, once OA developed, a higher BMD might increase the risk of osteophyte formation. Other studies have also reported a positive association between BMD and osteophytes, with a negative association with joint space narrowing [30, 31]. In an animal experiment, knee OA induction by anterior cruciate ligament transection in young growing female rats induced greater bone loss in the weight-bearing bone than in non-weight-bearing bone during OA progression [32]. From a cellular point of view, OP patients exhibit an imbalance between the osteoblast and osteoclast activity [33], and dysregulation of bone remodeling contributes to the development of OA [34]. In our study, we identified a sex-specific difference in the association between lumbar BMD and OA. One possible explanation is that higher $\mathrm{BMI}$ and greater weight-bearing activities, which are more likely in men than in women, might both increase the risk of damage to articular cartilage leading to $\mathrm{OA}$ and also be beneficial to the preservation of bone mass.
The absence of an association between OP and RA may be a result of multiple factors. Of note, a link between OP and RA has previously been postulated, with this association being mediated via several mechanisms, including pro-inflammatory state, glucocorticoids use, low level of physical activity, and the classic risk factors for OP [35]. However, in a cross-sectional study of 152 Korean adults $\geq 50$ years of age, Kweon et al. [36] found no significant difference in lumbar BMD between patients with and without RA. In a study of 138 postmenopausal women with RA, Mori et al. [37] found that disease duration was significantly related to BMD using multivariate linear regression analyses. In contrast, a study of 76 patients with RA identified a lower than expected BMD in patients in the first decade of their RA disease compared to reference population [38]. In a study of 299 Korean female patients with RA, Lee et al. [39] found no significant association between disease duration of RA and BMD. In our own analysis, we did not identify a significant association between BMD and $\mathrm{RA}$, or disease duration of RA, and this both in males and females. Differences across studies are likely attributable to variations among studies, including demographic characteristics, sample size, study design, and confounding variables controlled for.

The strengths of our study include a population-based sample with a wide age range that is generalizable to a community population, subgroup analyses for sensitivity test, and adjustment for many potential confounders. However, the limitations of our study also need to be

Table 2 Associations between arthritis and lumbar bone mineral density

\begin{tabular}{|c|c|c|c|}
\hline & Model $1, \beta(95 \% \mathrm{Cl}, P)$ & Model $2, \beta(95 \% \mathrm{Cl}, P)$ & Model $3, \beta(95 \% \mathrm{Cl}, P)$ \\
\hline Non-arthritis & Reference & Reference & Reference \\
\hline Arthritis & $0.007(-0.001,0.015) 0.0861$ & $0.017(0.008,0.025) 0.0001$ & $0.018(0.010,0.027)<0.0001$ \\
\hline Non-arthritis & Reference & Reference & Reference \\
\hline Osteoarthritis or degenerative arthritis & $0.013(0.001,0.025) 0.0293$ & $0.023(0.012,0.035) 0.0001$ & $0.023(0.011,0.035) 0.0001$ \\
\hline Rheumatoid arthritis & $0.000(-0.017,0.018) 0.9733$ & $0.010(-0.007,0.027) 0.2599$ & $0.014(-0.003,0.031) 0.1074$ \\
\hline Psoriatic arthritis & $0.005(-0.039,0.049) 0.8177$ & $0.020(0.000,0.039) 0.0445$ & $0.024(0.005,0.043) 0.0133$ \\
\hline Do not know or refused & $0.000(-0.015,0.015) 0.9712$ & $0.008(-0.006,0.023) 0.2665$ & $0.011(-0.004,0.026) 0.1350$ \\
\hline
\end{tabular}

Model 1 no covariates were adjusted; Model 2 age, gender, and race were adjusted; Model 3 age, gender, race, educational level, body mass index, ratio of family income to poverty, vigorous recreational activities, smoked at least 100 cigarettes in life, blood urea nitrogen, total protein, total cholesterol, alkaline phosphatase, serum uric acid, serum sodium, serum potassium, serum phosphorus, and serum calcium were adjusted 
Table 3 Subgroup analyses stratified by gender

\begin{tabular}{|c|c|c|c|}
\hline & Model $1, \beta(95 \% \mathrm{Cl}, P)$ & Model $2, \beta(95 \% \mathrm{Cl}, P)$ & Model $3, \beta(95 \% \mathrm{Cl}, P)$ \\
\hline \multicolumn{4}{|l|}{ Male } \\
\hline Non-arthritis & Reference & Reference & Reference \\
\hline Osteoarthritis or degenerative arthritis & $0.045(0.026,0.065)<0.0001$ & $0.053(0.034,0.072)<0.0001$ & $0.047(0.028,0.066)<0.0001$ \\
\hline Rheumatoid arthritis & $0.010(-0.016,0.036) 0.4569$ & $0.021(-0.005,0.046) 0.1139$ & $0.023(-0.003,0.048) 0.0776$ \\
\hline \multicolumn{4}{|l|}{ Female } \\
\hline Non-arthritis & Reference & Reference & Reference \\
\hline Osteoarthritis or degenerative arthritis & $-0.012(-0.026,0.003) 0.1158$ & $0.005(-0.010,0.020) 0.4922$ & $0.007(-0.008,0.021) 0.3526$ \\
\hline Rheumatoid arthritis & $-0.010(-0.034,0.013) 0.3941$ & $0.001(-0.022,0.024) 0.9418$ & $0.008(-0.015,0.031) 0.5157$ \\
\hline
\end{tabular}

Adjusted for age, race, educational level, body mass index, ratio of family income to poverty, vigorous recreational activities, smoked at least 100 cigarettes in life, blood urea nitrogen, total protein, total cholesterol, alkaline phosphatase, serum uric acid, serum sodium, serum potassium, serum phosphorus, and serum calcium

Table 4 Subgroup analyses stratified by race

\begin{tabular}{|c|c|c|c|}
\hline & Model 1, $\beta(95 \% \mathrm{Cl}, P)$ & Model $2, \beta(95 \% \mathrm{Cl}, P)$ & Model $3, \beta(95 \% \mathrm{Cl}, P)$ \\
\hline \multicolumn{4}{|l|}{ Non-Hispanic White } \\
\hline Non-arthritis & Reference & Reference & Reference \\
\hline Osteoarthritis or degenerative arthritis & $0.009(-0.009,0.026) 0.3439$ & $0.018(-0.000,0.036) 0.0501$ & $0.019(0.001,0.037) 0.0382$ \\
\hline Rheumatoid arthritis & $-0.015(-0.045,0.015) 0.3222$ & $-0.007(-0.036,0.023) 0.6699$ & $0.001(-0.028,0.031) 0.9232$ \\
\hline \multicolumn{4}{|l|}{ Non-Hispanic Black } \\
\hline Non-arthritis & Reference & Reference & Reference \\
\hline Osteoarthritis or degenerative arthritis & $-0.020(-0.050,0.009) 0.1806$ & $0.003(-0.027,0.034) 0.8340$ & $0.007(-0.024,0.037) 0.6611$ \\
\hline Rheumatoid arthritis & $0.008(-0.031,0.046) 0.6947$ & $0.032(-0.007,0.071) 0.1105$ & $0.032(-0.007,0.071) 0.1035$ \\
\hline \multicolumn{4}{|l|}{ Mexican American } \\
\hline Non-arthritis & Reference & Reference & Reference \\
\hline Osteoarthritis or degenerative arthritis & $0.015(-0.025,0.056) 0.4579$ & $0.032(-0.008,0.073) 0.1189$ & $0.017(-0.023,0.057) 0.4103$ \\
\hline Rheumatoid arthritis & $-0.022(-0.061,0.018) 0.2899$ & $-0.004(-0.044,0.036) 0.8602$ & $-0.006(-0.046,0.033) 0.7621$ \\
\hline
\end{tabular}

Adjusted for age, gender, educational level, body mass index, ratio of family income to poverty, vigorous recreational activities, smoked at least 100 cigarettes in life, blood urea nitrogen, total protein, total cholesterol, alkaline phosphatase, serum uric acid, serum sodium, serum potassium, serum phosphorus, and serum calcium

Table 5 Associations between disease duration of arthritis and lumbar bone mineral density

\begin{tabular}{lllll}
\hline Disease duration of arthritis (years) & Model $\mathbf{1}, \boldsymbol{\beta}(\mathbf{9 5} \% \mathbf{C l}) \boldsymbol{P}$ value & Model $\mathbf{2} \boldsymbol{\beta}(\mathbf{9 5 \%} \mathbf{C l}) \boldsymbol{P}$ value & Model $\mathbf{3}, \boldsymbol{\beta}(\mathbf{9 5} \% \mathbf{C l}) \boldsymbol{P}$ value \\
\hline Osteoarthritis or degenerative arthritis & $0.0005(-0.0021,0.0011) 0.5312$ & $-0.0003(-0.0020,0.0013) 0.6746$ & $-0.0001(-0.0017,0.0015) 0.8619$ \\
Rheumatoid arthritis & $0.0013(-0.0005,0.0032) 0.1596$ & $0.0013(-0.0005,0.0032) 0.1649$ & $0.0006(-0.0012,0.0025) 0.4979$ \\
\hline
\end{tabular}

Adjusted for age, race, educational level, body mass index, ratio of family income to poverty, vigorous recreational activities, smoked at least 100 cigarettes in life, blood urea nitrogen, total protein, total cholesterol, alkaline phosphatase, serum uric acid, serum sodium, serum potassium, serum phosphorus, and serum calcium 


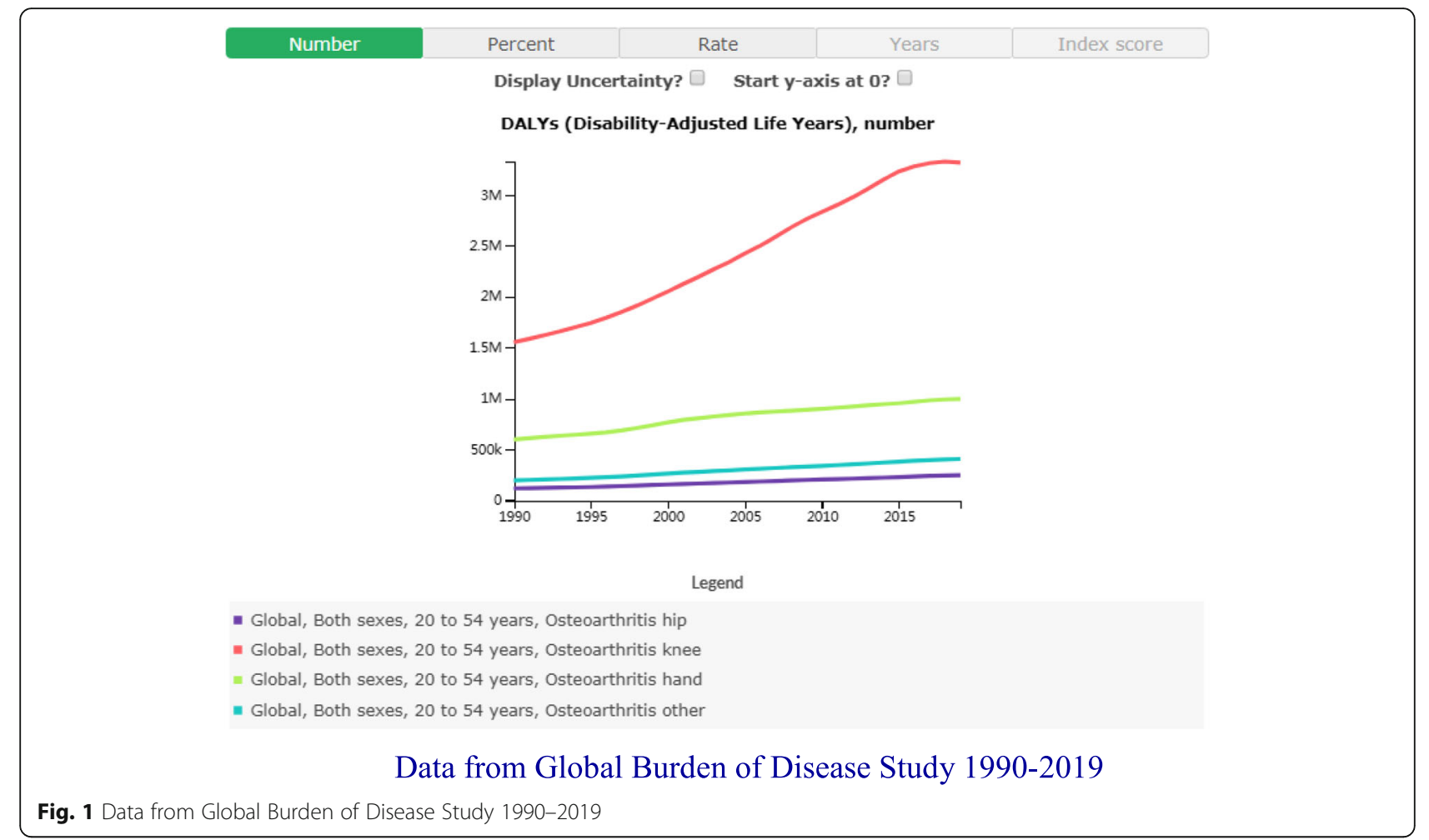

acknowledged. First, due to the cross-sectional design of our study, we were unable to elucidate the causal relationship between arthritis and BMD. Longitudinal studies investigating the causality between them are needed. Second, the diagnosis of arthritis was based on patients' self-report which may lead to bias. However, the consistency between self-reported arthritis and clinical confirmation has previously been documented [40, 41]. Third, the missing information on different sites of arthritis precludes us to estimate the associations between OA, RA, and BMD at specific sites. For example, primary osteoarthritis includes nonuniform joint space loss, osteophyte formation, cyst formation, and subchondral sclerosis at the lumbar spine which might increase the DXA measures of lumbar BMD, which is a considerable confounding factor in our study. However, the data from the Global Burden of Disease Study indicated that knee OA accounts for the vast majority of young and middleaged adults [42] (Fig. 1). Fourth, our study results cannot be generalized as we excluded populations with special health concerns, such as individuals with a history of cancer. Finally, there might be other confounding factors we did not control for in our study, such as the use of glucocorticoids used for the treatment of RA. We do note, however, a previous study which did not identify a significant association between the cumulative glucocorticoid dose and BMD after adjustment for confounding variables [39]. The results of a population-based study similarly showed no significant difference in BMD between patients with RA treated with corticosteroids and a non-steroid group, indicative that an independent effect of corticosteroids on BMD is likely negligible [43].

In summary, lumbar BMD was associated with $\mathrm{OA}$ but not RA. Moreover, we identified a sex-specific effect, with a higher lumbar BMD associated with OA in males, but not in females. Our findings may improve our understanding between OA, RA, and bone health. Additional studies examining the association between BMD and $\mathrm{OA}$ and RA are warranted to confirm our findings.

\section{Abbreviations}

OP: Osteoporosis; OA: Osteoarthritis; RA: Rheumatoid arthritis; BMD: Bone mineral density; NHANES: The National Health and Nutrition Examination Survey; US: The United States; NCHS: The National Center for Health Statistics; DXA: Dual-energy X-ray absorptiometry; BMI: Body mass index; STROBE: The Strengthening the Reporting of Observational Studies in Epidemiology

\section{Acknowledgements}

The authors appreciate the time and effort given by participants during the data collection phase of the NHANES project.

\section{Authors' contributions}

ZXZ, GFH, and FJ contributed to data collection, analysis, and writing of the manuscript. XCY contributed to study design and editing of the manuscript. The authors read and approved the final manuscript.

Funding

This study received no funding. 


\section{Declarations}

\section{Ethics approval and consent to participate}

The ethics review board of the National Center for Health Statistics approved all NHANES protocols and written informed consents were obtained from all participants.

\section{Consent for publication}

Not applicable.

\section{Competing interests}

The authors declare no competing interests.

\section{Author details}

'Department of Osteoporosis Care and Control, Xiaoshan Affiliated Hospital of Wenzhou Medical University, Hangzhou 311200, Zhejiang, China. ${ }^{2}$ Clinical Research Center, Xiaoshan Affiliated Hospital of Wenzhou Medical University, Hangzhou 311200, Zhejiang, China.

\section{Received: 1 January 2021 Accepted: 4 March 2021 \\ Published online: 15 March 2021}

\section{References}

1. Franco-Trepat E, Guillan-Fresco M, Alonso-Perez A, Jorge-Mora A, Francisco V, Gualillo O, Gomez R. Visfatin connection: present and future in osteoarthritis and osteoporosis. J Clin Med. 2019:8(8)

2. Barbour KE, Helmick CG, Boring M, Brady TJ. Vital Signs: Prevalence of doctor-diagnosed arthritis and arthritis-attributable activity limitation United States, 2013-2015. MMWR Morb Mortal Wkly Rep. 2017;66(9):246-53.

3. National Collaborating Centre for Chronic C. National Institute for Health and Clinical Excellence: Guidance. In: Rheumatoid arthritis: national clinical guideline for management and treatment in adults. London: Royal College of Physicians (UK) Royal College of Physicians of London.; 2009.

4. McInnes IB, Schett G. The pathogenesis of rheumatoid arthritis. N Engl J Med. 2011:365(23):2205-19.

5. Gomez R, Villalvilla A, Largo R, Gualillo O, Herrero-Beaumont G. TLR4 signalling in osteoarthritis--finding targets for candidate DMOADs. Nat Rev Rheumatol. 2015;11(3):159-70.

6. Geusens PP, van den Bergh JP. Osteoporosis and osteoarthritis: shared mechanisms and epidemiology. Curr Opin Rheumatol. 2016;28(2):97-103.

7. Clayton ES, Hochberg MC. Osteoporosis and osteoarthritis, rheumatoid arthritis and spondylarthropathies. Curr Osteoporosis Rep. 2013;11(4):257-62.

8. Ramonda R, Sartori L, Ortolan A, Frallonardo P, Lorenzin M, Punzi L, Musacchio $\mathrm{E}$. The controversial relationship between osteoarthritis and osteoporosis: an update on hand subtypes. Int J Rheum Dis. 2016;19(10): 954-60.

9. Im Gl, Kim MK. The relationship between osteoarthritis and osteoporosis. J Bone Miner Metab. 2014:32(2):101-9.

10. Dequeker J, Aerssens J, Luyten FP. Osteoarthritis and osteoporosis: clinical and research evidence of inverse relationship. Aging Clin Exp Res. 2003, 15(5):426-39.

11. Dillon CF, Weisman MH. US National Health and Nutrition Examination Survey Arthritis Initiatives, Methodologies and Data. Rheumatic Dis Clin North Am. 2018;44(2):215-65.

12. Zipf G, Chiappa M, Porter KS, Ostchega Y, Lewis BG, Dostal J. National health and nutrition examination survey: plan and operations, 1999-2010. Vital Health Stat Ser 1. 2013:(56):1-37.

13. Kanis JA, Johnell O. Requirements for DXA for the management of osteoporosis in Europe. Osteoporos Int. 2005:16(3):229-38.

14. von Elm E, Altman DG, Egger M, Pocock SJ, Gotzsche PC, Vandenbroucke JP. The Strengthening the Reporting of Observational Studies in Epidemiology (STROBE) statement: guidelines for reporting observational studies. Lancet. 2007;370(9596):1453-7.

15. Povoroznyuk W, Zaverukha NV, Musiienko AS. Bone mineral density and trabecular bone score in postmenopausal women with knee osteoarthritis and obesity. Wiad Lek. 2020;73(3):529-33.

16. Kim YH, Lee JS, Park JH. Association between bone mineral density and knee osteoarthritis in Koreans: the Fourth and Fifth Korea National Health and Nutrition Examination Surveys. Osteoarthr Cartil. 2018;26(11):1511-7.

17. Bergink AP, Rivadeneira F, Bierma-Zeinstra SM, Zillikens MC, Ikram MA, Uitterlinden AG, van Meurs JBJ. Are bone mineral density and fractures related to the incidence and progression of radiographic osteoarthritis of the knee, hip, and hand in elderly men and women? The Rotterdam Study. Arthritis Rheum. 2019;71(3):361-9.

18. Stone KL, Seeley DG, Lui LY, Cauley JA, Ensrud K, Browner WS, Nevitt MC, Cummings SR. BMD at multiple sites and risk of fracture of multiple types: long-term results from the Study of Osteoporotic Fractures. J Bone Miner Res. 2003;18(11):1947-54

19. Cummings SR, Cawthon PM, Ensrud KE, Cauley JA, Fink HA, Orwoll ES. BMD and risk of hip and nonvertebral fractures in older men: a prospective study and comparison with older women. J Bone Miner Res. 2006;21(10):1550-6.

20. Chan MY, Center JR, Eisman JA, Nguyen TV. Bone mineral density and association of osteoarthritis with fracture risk. Osteoarthr Cartil. 2014;22(9): 1251-8.

21. Lingard EA, Mitchell SY, Francis RM, Rawlings D, Peaston R, Birrell FN, McCaskie AW. The prevalence of osteoporosis in patients with severe hip and knee osteoarthritis awaiting joint arthroplasty. Age Ageing. 2010;39(2): 234-9.

22. Aigul Z, Peyman Y. The relationship between osteoarthritis and osteoporosis in patients with primary generalized osteoarthritis. Turkish J Rheumat. 2013; 28(3):163-72.

23. Deng ZH, Zeng C, Li YS, Yang T, Li H, Wei J, Lei GH. Relation between phalangeal bone mineral density and radiographic knee osteoarthritis: a cross-sectional study. BMC Musculoskelet Disord. 2016;17:71.

24. Hunter DJ, Spector TD. The role of bone metabolism in osteoarthritis. Curr Rheumatol Rep. 2003:5(1):15-9.

25. Ding C, Cicuttini F, Jones G. Tibial subchondral bone size and knee cartilage defects: relevance to knee osteoarthritis. Osteoarthr Cartil. 2007;15(5):479-86.

26. Javaid MK, Lane NE, Mackey DC, Lui LY, Arden NK, Beck TJ, Hochberg MC, Nevitt MC. Changes in proximal femoral mineral geometry precede the onset of radiographic hip osteoarthritis: the study of osteoporotic fractures. Arthritis Rheum. 2009;60(7):2028-36.

27. Nelson AE, Golightly YM, Renner JB, Schwartz TA, Liu F, Lynch JA, Gregory JS, Aspden RM, Lane NE, Jordan JM. Variations in hip shape are associated with radiographic knee osteoarthritis: cross-sectional and longitudinal analyses of the Johnston County Osteoarthritis Project. J Rheumatol. 2016; 43(2):405-10.

28. Yau MS, Yerges-Armstrong LM, Liu Y, Lewis CE, Duggan DJ, Renner JB, Torner J, Felson DT, McCulloch CE, Kwoh CK, et al. Genome-wide association study of radiographic knee osteoarthritis in North American Caucasians. Arthritis Rheumatol. 2017:69(2):343-51.

29. Zhang Y, Hannan MT, Chaisson CE, McAlindon TE, Evans SR, Aliabadi P, Levy D, Felson DT. Bone mineral density and risk of incident and progressive radiographic knee osteoarthritis in women: the Framingham Study. J Rheumatol. 2000;27(4):1032-7.

30. Hart DJ, Cronin C, Daniels M, Worthy T, Doyle DV, Spector TD. The relationship of bone density and fracture to incident and progressive radiographic osteoarthritis of the knee: the Chingford Study. Arthritis Rheum. 2002:46(1):92-9.

31. Wen L, Shin MH, Kang JH, Yim YR, Kim JE, Lee JW, Lee KE, Park DJ, Kim TJ, Park YW, et al. The relationships between bone mineral density and radiographic features of hand or knee osteoarthritis in older adults: data from the Dong-gu Study. Rheumatology. 2016;55(3):495-503.

32. Namhong S, Wongdee $K$, Suntornsaratoon $P$, Teerapornpuntakit Hemstapat R, Charoenphandhu N. Knee osteoarthritis in young growing rats is associated with widespread osteopenia and impaired bone mineralization. Sci Rep. 2020;10(1):15079.

33. Scimeca M, Salustri A, Bonanno E, Nardozi D, Rao C, Piccirilli E, Feola M, Tancredi V, Rinaldi A, lolascon G, et al. Impairment of PTX3 expression in osteoblasts: a key element for osteoporosis. Cell Death Dis. 2017;8(10):e3125.

34. Maruotti N, Corrado A, Cantatore FP. Osteoblast role in osteoarthritis pathogenesis. J Cell Physiol. 2017;232(11):2957-63.

35. Ibanez M, Ortiz AM, Castrejon I, Garcia-Vadillo JA, Carvajal I, Castaneda S, Gonzalez-Alvaro I. A rational use of glucocorticoids in patients with early arthritis has a minimal impact on bone mass. Arthritis Res Ther. 2010:12(2): R50.

36. Kweon SM, Sohn DH, Park JH, Koh JH, Park EK, Lee HN, Kim K, Kim Y, Kim GT, Lee SG. Male patients with rheumatoid arthritis have an increased risk of osteoporosis: frequency and risk factors. Medicine (Baltimore). 2018:97(24): e11122.

37. Mori Y, Kuwahara Y, Chiba S, Kogre A, Baba K, Kamimura M, Itoi E. Bone mineral density of postmenopausal women with rheumatoid arthritis 
depends on disease duration regardless of treatment. J Bone Miner Metab. 2017;35(1):52-7.

38. Kroot EJ, Nieuwenhuizen MG, de Waal Malefijt MC, van Riel PL, Pasker-de Jong PC, Laan RF. Change in bone mineral density in patients with rheumatoid arthritis during the first decade of the disease. Arthritis Rheum. 2001;44(6):1254-60.

39. Lee SG, Park YE, Park SH, Kim TK, Choi HJ, Lee SJ, Kim SI, Lee SH, Kim GT, Lee JW, et al. Increased frequency of osteoporosis and BMD below the expected range for age among South Korean women with rheumatoid arthritis. Int J Rheum Dis. 2012;15(3):289-96.

40. El Miedany Y, El Gaafary M, Youssef SS, Palmer D. Incorporating patient reported outcome measures in clinical practice: development and validation of a questionnaire for inflammatory arthritis. Clin Exp Rheumatol. 2010;28(5): 734-44.

41. March LM, Schwarz JM, Carfrae BH, Bagge E. Clinical validation of selfreported osteoarthritis. Osteoarthr Cartil. 1998;6(2):87-93.

42. The Global Burden of Disease Study tool. http://ghdx.healthdata.org/gbdresults-tool.

43. Kroger H, Honkanen R, Saarikoski S, Alhava E. Decreased axial bone mineral density in perimenopausal women with rheumatoid arthritis--a population based study. Ann Rheum Dis. 1994;53(1):18-23.

\section{Publisher's Note}

Springer Nature remains neutral with regard to jurisdictional claims in published maps and institutional affiliations.

Ready to submit your research? Choose BMC and benefit from:

- fast, convenient online submission

- thorough peer review by experienced researchers in your field

- rapid publication on acceptance

- support for research data, including large and complex data types

- gold Open Access which fosters wider collaboration and increased citations

- maximum visibility for your research: over $100 \mathrm{M}$ website views per year

At $\mathrm{BMC}$, research is always in progress.

Learn more biomedcentral.com/submissions 